\title{
The role of nano-particles in the field of thermal spray coating technology
}

\author{
Stephan Siegmann, Marc Leparoux, Lukas Rohr \\ EMPA - Swiss Federal Institute for Materials Research and Technology \\ Feuerwerkerstrasse 39, CH-3602 Thun, Switzerland
}

\begin{abstract}
:
Nano-particles play not only a key role in recent research fields, but also in the public discussions about health and safety in nanotechnology. Nevertheless, the worldwide activities in nano-particles research increased dramatically during the last 5 to 10 years. There are different potential routes for the future production of nano-particles at large scale. The main directions envisaged are mechanical milling, wet chemical reactions or gas phase processes. Each of the processes has its specific advantages and limitations. Mechanical milling and wet chemical reactions are typically time intensive and batch processes, whereas gas phase productions by flames or plasma can be carried out continuously. Materials of interest are mainly oxide ceramics, carbides, nitrides, and pure metals. Nano-ceramics are interesting candidates for coating technologies due to expected higher coating toughness, better thermal shock and wear resistance. Especially embedded nano-carbides and -nitrides offer homogenously distributed hard phases, which enhance coatings hardness.
\end{abstract}

Thermal spraying, a nearly 100 years old and world wide established coating technology, gets new possibilities thanks to optimized, nano-sized and/or nano-structured powders. Latest coating system developments like high velocity flame spraying (HVOF), cold gas deposition or liquid suspension spraying in combination with new powder qualities may open new applications and markets.

This article gives an overview on the latest activities in nano-particle research and production in special relation to thermal spray coating technology.

\section{Introduction}

Nanoparticles have been produced in commercial quantities for many years. The most important representatives are carbon black (Cabot, Degussa, Columbia etc.), fumed silica (Cabot, Degussa) and pigmentary titania (DuPont, Millenium, Kerr-McGee, Ishihara), nickel and iron powders (BASF , INCO), nanostructured carbides, nitrides, borides and other non-oxide ceramics (Dow, H.C. Stark) [1].

Anselmann described in an overview article in $200 \mathrm{I}$ many examples of nanoparticles and nanolayers already existing in commercial applications [2], like wet ground mica platelets used as fillers in plastics and cosmetics. Mono-, or polydisperse silica spheres can be covered with $\mathrm{TiO}_{2}$ nano-particles (see Figure I) to absorb UV light and adapt the refractive index or by $\mathrm{Fe}_{2} \mathrm{O}_{3}$ to produce magnetic particles [2]. 

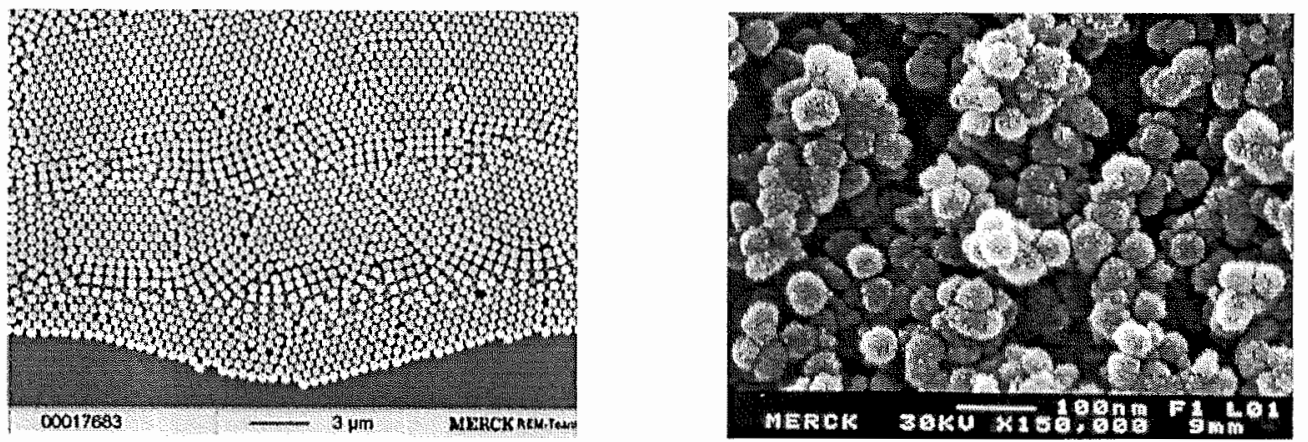

Figure 1: Monodispersed silica spheres (left) and coated with $\mathrm{TiO}_{2}$ particles of less than $10 \mathrm{~nm}$ (right) [2].

\section{Thermal Spray Technology}

Thermal spray coating technology uses powders according to the European standard EN 1274 [3] or equivalent ISO 14232 [4], or wires, rods and cords according to EN ISO 14919 [5]. These starting materials are introduced in different heat sources like flames or plasma to be melted and accelerated before being splashed at the surfaces of the substrates or components, respectively. Repeated transition of the spray gun across the substrate builds up a dense coating layer from a few ten microns up to millimetre thickness.

During the last century, various spray techniques have been developed, which are described in the European standard EN 657 [6] or equivalent ISO 14917 [7]. Among the numerous coating systems, High Velocity Oxy/Fuel (HVOF) spraying and Plasma Spraying (PS) seem to be the most promising candidates for the processing of nano-materials, due to their high processing speed or high thermal energy.

\section{Nanomaterials for Thermal Spraying}

\subsection{Nanostructured Powders}

The oldest Nanotechnology known in materials technology is probably precipitation hardening [8,9]. The spraying of conventional coatings containing precipitation hardenable species [10-15] offered the possibilities of tuneable nanostructure even before the public discussion on nanotechnology started. The advantage of precipitation hardening lies in the classical utilization of well-established production technologies, but offering the advantage of designable submicrostructure in a well known base material. These nanostructured materials showed already in the past increased mechanical properties in bulk steels $[9,10,16]$ or in reactively thermally sprayed coatings $[11,12,15]$.
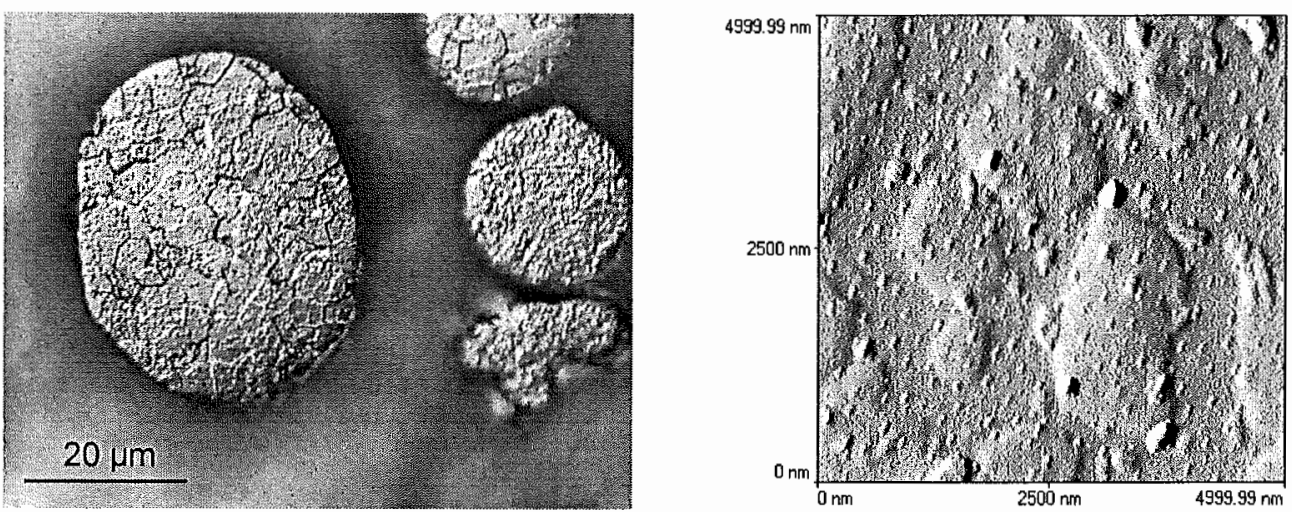

Figure 2: Metallographic cross section of austenitic steel particles of type Fe17Cr10Mn6VMo containing alloyed Vanadium as most Nitrogen affine element to form secondary nitrides of nanometre size (see AFM picture (right) showing sticking out hard phases of type $V N$ ). 
The advantage of this class of nano-structured materials is the applicability of conventional production methods like alloying, casting, forging, and of course thermal spraying.

The application of nano-scaled powders needs in general special adaptations of the following process depending on the types of nanoparticles used, whether they are wet or dry or agglomerated.

\subsection{Nanopowders}

There are different processing routes that can achieve the production of nanoparticles. Nevertheless, there are two distinct ways of approach. One route is called "top down" and can be reached e.g. by crushing and milling large pieces down to nanometre sized particles. The second route follows the so-called "bottom up" approach, e.g. by thermal evaporation of materials followed by condensation and controlled particle growth up to the desired size range. These routes offer tremendous control of the final bulk material properties since the chemical composition, the size and the interparticle spacing can be tailored up from the nano range. Different kind of passivation and functionalisation processes can successfully reduce the effect of undesired nanoparticle cluster growth and give access to 2- and 3dimensional ordered aggregate structures and new functional materials [17]

One of the routes that offer high purity nanoparticles from precipitation processes are the wet chemical methods.

\section{Wet chemical synthesis:}

Nanoparticles with different morphologies can be produced by wet chemical routes. The key parameters controlling the precipitation process in the liquid are e.g. concentration of the solution, $\mathrm{pH}$ values and the washing media [14]. These parameters influence the phase transformation reactions and the particles recrystallisation processes. Using special surface controlling agents (SCAs) the nucleation, agglomeration and growth of the nanoparticles can be influenced, or even coating of nanoparticles by a functional layer of a few nanometer thicknesses can be realised [18].

\section{Methods for nano-carbide production such as $\mathrm{WC}, \mathrm{SiC}, \mathrm{B}_{4} \mathrm{C}$}

The traditional method of making cemented carbide powders is by crushing, grinding, and consolidation e.g. by sintering with different binders to micron scale particles. These powders can afterwards be used, i.e. further treated or fed, like any conventional powders. In addition, refractory metal-carbide composites, like WC-Co can be produced by wet chemical routes as well. Starting e.g. with an aqueous solution of $\mathrm{CoCl}_{2}$ and mixing with $\mathrm{H}_{2} \mathrm{WO}_{4}$ in ethylenediamine to precipitate crystals of $\mathrm{CO}_{3} \mathrm{WO}_{4}$ and afterwards reductively decomposition to form nanoporousnanophase W-Co powder [19]. The conversion to WC-Co is further done by reaction with $\mathrm{CO}_{2}-\mathrm{CO}$ gas at pressure of 900 Torr and temperatures between $850{ }^{\circ} \mathrm{C}$ and $750{ }^{\circ} \mathrm{C}$ within approximately 30 minutes up to 5 hours, respectively. Other carburizing agents can be used such as carbon black $\left(1^{\prime} 400^{\circ} \mathrm{C}\right)$, or gaseous hydrocarbons $\left(\mathrm{CH}_{4}\right.$ or $\left.\mathrm{C}_{2} \mathrm{H}_{4}\right)$ at temperatures below $700{ }^{\circ} \mathrm{C}[20]$.

Other economical routes of mass production are e.g. Chemical Vapour Condensation methods.

Combustion Flame-Chemical Vapour Condensation (CF-CVC) was first described by Gleiter and co-workers in 1989 [21]. The concept consists of rapid vapour phase condensation synthesis to produce non-agglomerated nanoparticles by rapid condensation from the vapour phase in a reduced pressure environment. This goal can be achieved by a combustion burner or a hot wall reactor, where the chemical precursors are pyrolysed. The key parameters for a CF-CVC process are gas phase residence time, the temperature of the flames or the hot-wall reactor, and precursor concentration in the carrier gas $[22,23]$. Recent studies showed the scalability of the Chemical Vapor Condensation process with production rates of up to $50 \mathrm{~g} / \mathrm{h}$ by replacing the hot-wall reactor with a flat flame combustor, even operable at low pressures [22]. Nanopowders of $\mathrm{SiO}_{2}$ produced by this process showed a surface area of $270-360 \mathrm{~m}^{2} / \mathrm{g}$ and nano- $\mathrm{TiO}_{2}$ of $70-80 \mathrm{~m}^{2} / \mathrm{g}$ [22]. Singhal and co-workers have been seeking for different crystallographic orientations and minimised aggregation effects in flame synthesized $\mathrm{V}_{2} \mathrm{O}_{5}$ nanoparticles [24]. Theoretical understanding of the nanoparticle growth in gas phase processes was proposed by Kruis et al. in 1993 by a simple model describing the evolution characteristics of aggregates due to coagulation and sintering [25]. This model can be adapted to other thermal processes like plasma evaporation and condensation or other particle material species [26, 27].

State of the art nanoparticles produced by flame pyrolysis processes and available on market for a long time are e.g. $\mathrm{SiO}_{2}$ or $\mathrm{TiO}_{2}\left(\right.$ Aerosil ${ }^{\circledR}$, Cab-o-sil $\left.{ }^{\circledR}\right)$. They have been used in the past even in thermal spray business manly as fluidisation aids (in small mass amounts) for non- or poorly flowable thermal spraying powders. The high surface areas 
act as "nano-ball-bearings" between the often blocky particles and the low mass content necessary to increase the flowability of the macro sized spray powders significantly (typically below $2 \%$-wt) is often below the detection limit. Another important gas phase process used in the past is the carbothermal reduction synthesis.

Rapid carbothermal reduction (RCR) synthesis of ultra fine carbide powders was one of the most efficient and promising production ways in the 1990's [28-30]. High surface area carbon powders of Boron, Tungsten or Silicon can be produced within less than one second at temperatures exceeding approximately 2'200 K [28]. Weimer and co-authors produced $\mathrm{B}_{4} \mathrm{C}$ powders by the RCR process, that showed a high surface area between 12 and $32 \mathrm{~m}^{2} / \mathrm{g}$ and particle morphologies similar to other gas phase routes [28]. The most important steps of the formation of boron carbides by the carbothermal reduction process of boron oxide seems to be the phase change from solid to liquid to gaseous boron suboxides and the effect of reactive environment (like chemical composition, heating rate and final temperature) on the ending product.

The production of 5-12 $\mathrm{nm}$ carbon material $\left(\mathrm{W}_{2} \mathrm{C}\right)$ with ultrahigh surface area (measured by BET method of about $3^{\prime} 234 \mathrm{~m}^{2} / \mathrm{g}$ ), by the carbothermal hydrogen reduction (CHR) process at temperatures of $900{ }^{\circ} \mathrm{C}$, was reported by Liang et al. [30]. However, the resulting carbide surface is often contaminated by polymeric carbon from the pyrolysis of the carbon-containing gases (like e.g. $\mathrm{CH}_{4}, \mathrm{C}_{2} \mathrm{H}_{6}, \mathrm{C}_{4} \mathrm{H}_{10}$ or $\mathrm{CO}$ ) and this polymeric carbon is difficult to be removed. An alternative way of nanoparticle production uses microwaves as energy source.

Microwave processing of nanoparticles at standard industry frequencies of 0.915 and $2.45 \mathrm{GHz}$ is described by different authors [31-36].

The processing steps are similar to the other above mentioned gas phase processes: The precursors, typically chlorides, carbonyls or metal organic compounds, are introduced as vapours into a reaction tube - made typically of quartz glass directly in front of a plasma zone created by high electromagnetic fields in the microwave cavity. In the reaction zone, the precursors will be at least partly dissociated and ionised and nanoparticles are formed on cooling. The particles leave the microwave plasma with high electrical charges of the same sign thus avoiding agglomeration [36]. Even coated nanoparticles can be produced using directly a subsequent second plasma process. Thus the interaction of the particles can be adjusted using a polymer based nano-coating such, that the cores are kept on well-defined distances [36].

\subsection{Nanoparticle Suspensions}

The preparation of stable suspensions is a prerequisite for any further processing [37]. Schuetz and Piesche proposed a mathematical model for calculating floc size distributions for coagulating particles (dispersed quartz) in aqueous suspension (demineralised water with natrium hydroxide $\mathrm{NaOH}$ and calcium chloride $\mathrm{CaCl}_{2}$ ) with turbulent flow, which showed the significant influence of the local energy input in the coagulation reactor [38].

Keblinski et al. showed that the heat flow in suspensions with nano-sized particles, so called nanofluids, can be increased by factors of hundreds or thousands compared to conventional heat-transfer fluids, which could not only be explained by Brownian motion, but rather by ballistic phonon transport [39]. This effect would give reason to the advantage use of nanoparticle suspensions for thermal spraying, as this seems to be the only way, how the heat of an external heat sources, like in plasma processes, can easily be transported within the suspension.

\section{Thermal Spraying of Nanomaterials}

One of the problems to overcome with nanoparticles is the momentum needed to fully penetrate a flame or plasma for further treatment, i.e. melting, accelerating and splashing on the component. As the diameter of the particles decreases, the aerodynamic diameter is becoming the dominating factor. The inertia of the nanoparticles gets small and therefore they will follow nearly perfectly any flow field and never fully enter the plasma to be further treated in.

This problem can be solved either by a preliminary step of soft particle agglomeration or by mixing the nanoparticles in a suspension. The liquid of the suspension then reacts as a carrier and may even contribute additional energy to the process.

The suspension, containing the nanograins, is often injected radially in the plasma jet followed by a vaporisation process. The control of the injection conditions of suspensions containing nanograins of alumina in a DC plasma was described e.g. by Wittmann [40]. During in-plasma flight, the liquid is immediately vaporised and melting, 
agglomeration and sintering of the nanograins starts. Poirier et al. suggested first a model of aerosol flame spraying and impact processes of submicron particles [41, 42].

Bouyer, Gitzhofer, and Boulos presented in 1996 a parametric study of suspension plasma sprayed hydroxyapatite. Another promising application was the preparation of perovskite powders and coatings by RF-suspension plasma spraying [43] for solid fuel cell applications. The coatings obtained by suspension spraying are showing mainly an open porous structure (Figure 3).

\section{Results and Discussion}

Worldwide, many research groups are working on the use of nanoparticles for thermal spraying. Most of them are following the liquid suspension route [40,41,44-56], where the liquid has to be continuously pumped to the thermal spray torch. A very precise injection into the plasma is important for the following pyrolysation and nanoparticle formation process. A prerequisite using liquid suspensions is the stabilization of the suspension against sedimentation and agglomeration. The materials used in suspensions are manly oxides like calcium phosphate (hydroxyapatite) delivering porous coatings for biomedical applications, Alumina or Zirconia. The coatings produced are showing often a nano- up to submicron porosity, which in case of porous layers for fuel cells or biomedical applications can be advantageous due to their high exchange surface areas.
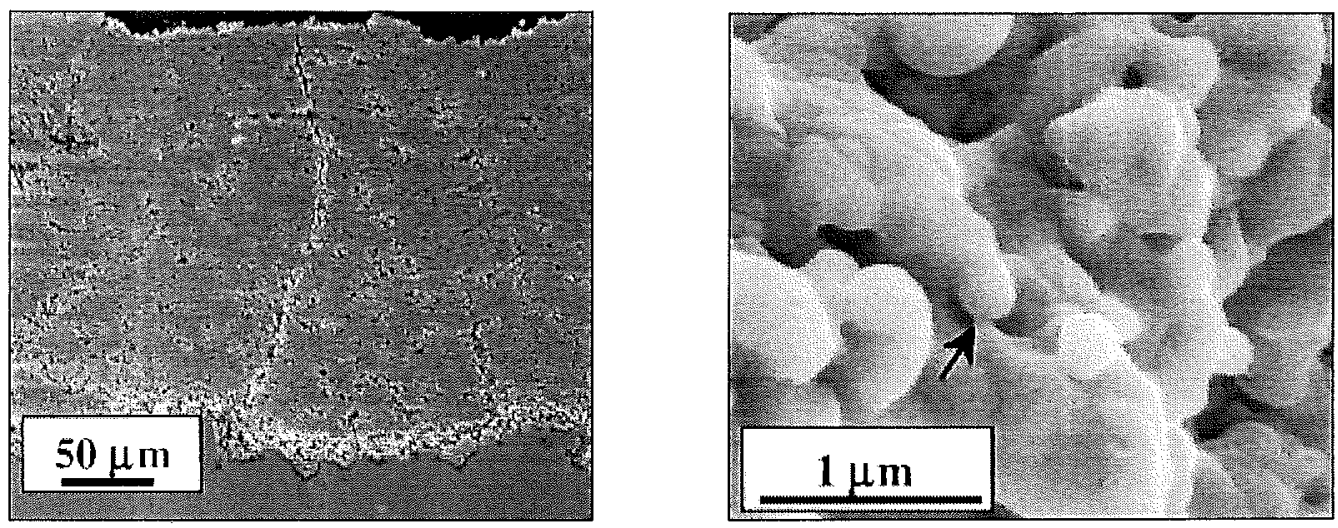

Figure 3: Nanoporous coatings obtained by liquid suspension plasma spraying of $\mathrm{ZrO}_{2}$ [57].

The use of precipitation hardenable materials was mentioned earliest $[11,12,16,58]$. Their use facilitates production technologies like thermal spraying, because no special feeding mechanism is needed. The use of reactive plasma species like $\mathrm{N}_{2}$ or $\mathrm{C}_{2} \mathrm{H}_{4}$ induces the precipitation process forming nitrides (Figure 4) or carbides, respectively.
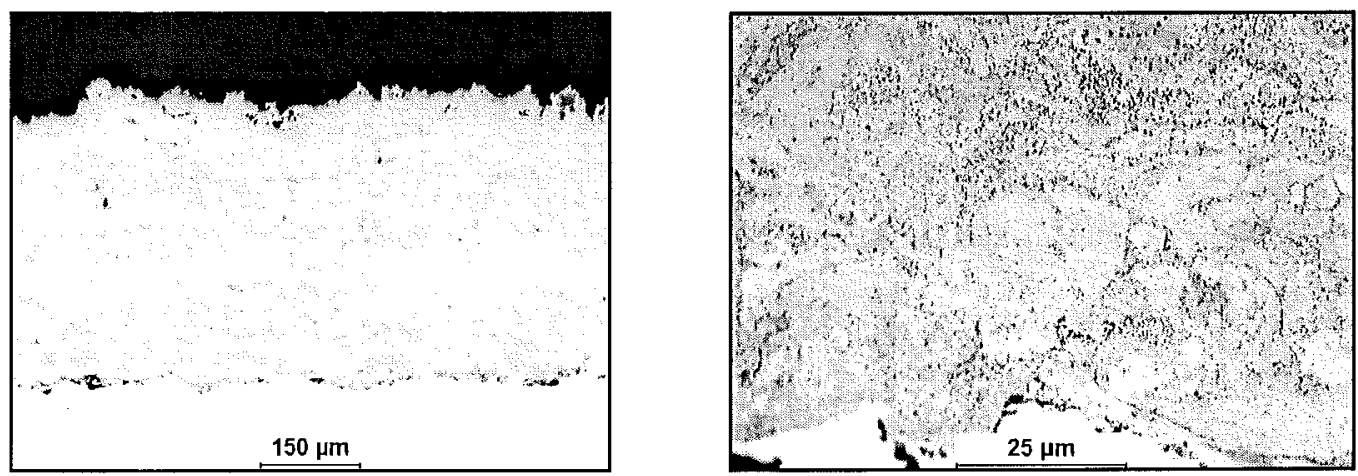

Figure 4: Left: Thermal sprayed coating using prealloyed and precipitation hardenable powders type Fe $17 \mathrm{Cr} 10 \mathrm{Mn} 6 \mathrm{VM}$ o during reactive vacuum plasma spraying. Dark spots on the right picture represent the locations of Nitrides after wet chemical etching. 


\section{Conclusions}

Nanoparticles play already a key role in many technological fields like fillers and pigments in paints and lacquers. Within thermal spraying technology so far, the use of nanoparticulate starting materials is manly concentrated at universities and research laboratories level.

Nevertheless, promising coating properties shown at laboratory scale may be interesting candidates even for mass production. The question of costs and availability of starting materials needs to be addressed and clearly answered, as well as the aspect of process efficiency and environmental concerns.

\section{References}

[1] Pratsinis, S. E.: Nanoparticles: synthesis, technology and applications; a key note lecture.

[2] Anselmann, R.: Nanoparticles and Nanolayers In Commercial Applications, Journal of Nanoparticle Research 3 (2001), p. 329-336.

[3] EN 1274: Thermal spraying - Powders - Composition - Technical supply conditions.

[4] ISO 14232: Thermal spraying - Powders - Composition and technical supply conditions

[5] EN ISO 14919: Thermal spraying - Wires, rods and cords for flame and arc spraying - Classification - Technical supply conditions.

[6] EN 657: Thermal spraying; terminology, classification.

[7] ISO 14917: Thermal spraying - Terminology, classification.

[8] Hornbogen, E.: Precipitation hardening - the oldest nanotechnology, Metall 55 (2001), p. 522-526.

[9] Speidel, M. O.: Entwicklung von Stickstofflegierten Austenitischen Stählen Höchster Festigkeit, (1994), p. 1-130.

[10] Uggowitzer, P. J.: Festigkeit und Zähigkeit austenistischer Stickstoffstähle, ( ), p. 115.

[11] Brandt, O. C., S. Siegmann and H.-P. Isch: HVOF- and VPS-Coatings Using Nanostructured Iron-Based Alloys, Proceedings of 1st United Thermal Spray Conference - Thermal Spray: A United Forum for Scientific and Technological Advances (1997), p. 875-876.

[12] Brandt, O. and S. D. Siegmann: VPS Coatings Using Nanostructural Iron-Based Alloys, Proceedings of 15th International Thermal Spray Conference - Thermal Spray: Meeting the Challenges of the 21st Century 2 (1998), p. $1249-1253$.

[13] He, J. and E. J. Lavernia: Precipitation Phenomenon in Nanostructured $\mathrm{Cr}_{3} \mathrm{C}_{2}-\mathrm{NiCr}$ Coatings, Materials Science and Engineering: A 301 (2001), p. 69-79.

[14] Rodríguez-Paéz, J. E., A. C. Caballero, M. Villegas, C. Moure, P. Durán and J. F. Fernández: Controlled precipitation methods: formation mechanism of $\mathrm{ZnO}$ nanoparticles, Journal of the European Ceramic Society 21 (2001), p. 925-930.

[15] Siegmann, S., O. Brandt and M. Dvorak: Thermally Sprayed Wear Resistant Coatings with Nanostructured Hard Phases, Journal of Thermal Spray Technology 13 (2004), p. 37-43.

[16] Bähre, W.-F., C. Solenthaler, P. J. Uggowitzer and M. O. Speidel: Hardenable Austenitic Iron Base Metal-MatrixComposites, Proceedings of PM Tech '97 (1997), p. 12.

[17] Storhoff, J. J., R. C. Mucic and C. A. Mirkin: Strategies for Organizing Nanoparticles into Aggregate Structures and Functional Materials, Journal of Cluster Science 8 (1997), p. 179-216.

[18] Schmidt, H.: Nanoparticles by chemical synthesis, processing to materials and innovative applications, Applied Organometallic Chemistry 15 (2001), p. 331-433.

[19] McCandlish, L. E., B. H. Kear and B. K. Kim: Chemical processing of nanophase WC-Co composite powders, Materials Science and Technology 6 (1990), p. 953-957.

[20] Gao, L. and B. H. Kear: Low temperature carburization of high surface area tungsten powders, Nanostructured Materials 5 (1995), p. 555-569.

[21] Gleiter H. Nanocrystalline Materials, Prog. Mater. Sci. 1989; 33: 223-315.

[22] Chen, Y., N. Glumac, B. H. Kear and G. Skandan: High rate synthesis of nanophase materials, Nanostructured Materials 9 (1997), p. 101-104. 
[23] Skandan, G., E. Heims, N. Glumac, Y.-J. Chen, F. Cosandey and B. H. Kear: Combustion Flame-Chemical Vapor Condensation: A New Technology for Production of Nanostructured Powders and Coatings, Proceedings of Thermal Spray Processing of Nanoscale Materials (1997), p.

[24] Singhal, A., G. Skandan, N. Glumac and B. H. Kear: Minimizing Aggregation Effects in Flame Synthesized Nanoparticles, Scripta Materialia 44 (2001), p. 2203-2207.

[25] Kruis, F. E., K. A. Kusters and S. E. Pratsinis: A Simple Model for the Evolution of the Characteristics of Aggregate Particles Undergoing Coagulation and Sintering, Aerosol Science and Technology 19 (1993), p. 514526.

[26] Leparoux, M. and S. Siegmann: Development of a filtration unit with a by-pass sampling system for nanoparticle collection, Proceedings of Filtech Europa 2003 - International Conference and Exhibition Filtration and Separation Technology (2003), p. II-242 - II-248.

[27] Schreuders, C., M. Leparoux, J.-W. Shin, M. Dvorak and S. Siegmann: Nanosized tungsten carbide powder produced by thermal plasma, Proceedings of Partec 2004 - International Congress for Particle Technology (2004), p. 16.4.

[28] Weimer, A. L., W. G. Moore, R. P. Roach, J. E. Hitt, R. S. Dixit and S. E. Pratsinis: Kinetics of Carbothermal reduction Synthesis of Boron Carbide, Journal of the American Ceramic Society 75 (1992), p. 2509-25I4.

[29] Dunmead, S. D., W. G. Moore, A. W. Weimer, G. A. Eisman and J. P. Henley: Method for making submicrometer carbides, submicrometer solid solution carbides, and the material resulting thereform, (1995), p. 11.

[30] Liang, C., F. Tian, Z. Wei, Q. Xin and C. Li: The synthesis of nanostructured W2C on ultrahigh surface area carbon materials via carbothermal hydrogen reduction, Nanotechnology 14 (2003), p. 955-958.

[31] Vollath, D. and K. E. Sickafus: Synthesis of nanosized ceramic nitride powders by microwave supported plasma reactions, Nanostructured Materials 2 (1993), p. 451-456.

[32] Vollath, D., D. V. Szabó and J. Hausselt: Synthesis and Properties of Ceramic Nanoparticles and Nanocomposites, Journal of the European Ceramic Society 17 (1997), p. 1317-1324.

[33] Vollath, D. and D. V. Szabó: Microwave plasma synthesis of ceramic nanapowders, Journal of Aerosol Science 28 (1997), p. S685-S688.

[34] Vollath, D. and D. V. Szabo: Synthesis of nanocrystalline $\mathrm{MoS}_{2}$ and $\mathrm{WS}_{2}$ in a microwave plasma, Materials Letters 35 (1998), p. 236-244.

[35] Liu, G., H. Gu and Q. Chen: Preparation of nanosized Mo powder by microwave plasma chemical vapor deposition method, Materials Chemistry and Physics 59 (1999), p. 204-209.

[36] Vollath, D. and D. V. Szabo: Coated Nanoparticles: A New Way to Improved Nanocomposites, Journal of Nanoparticle Research 1 (1999), p. 235-242.

[37] Monterrubio-Badillo, C., T. Chartier, H. Ageorges, J.-F. Coudert and P. Fauchais: Preparation of stable suspensions of perovskites for plasma spraying, Materials Science Forum 442 (2002), p.

[38] Schuetz, S. and M. Piesche: A mathematical model of coagulation processes, Separation and Purification Technology 26 (2002), p. 61-68.

[39] Keblinski, P., S. R. Phillpot, S. U. S. Choi and J. A. Eastman: Mechanisms of heat flow in suspensions of nanosized particles (nanofluids), International Journal of Heat and Mass Transfer 45 (2002), p. 855-863.

[40] Wittmann, K., F. Blein, J. F. Coudert and P. Fauchais: Control of the Injection of an Alumina Suspension Containing Nanograins in a DC Plasma, Proceedings of Thermal Spray 2001 - New Surfaces for a New Millennium (2001), p. 375-382.

[41] Poirier, T., A. M. Vardelle, M. F. Elchinger, M. Vardelle, A. Grimaud and H. Vesteghem: Modeling of the Acceleration and Behavior at Impact of Ceramic Suspension Droplets in Aerosol Flame Spraying, Proceedings of Thermal Spray 2001 - New Surfaces for a New Millennium (2001), p. 917-924.

[42] Poirier, T., A. Vardelle, M. F. Elchinger, M. Vardelle, A. Grimaud and H. Vesteghem: Deposition of Nanoparticle Suspensions by Aerosol Flame Spraying: Model of the Spray and Impact Processes, Journal of Thermal Spray Technology 12 (2003), p. 393-402.

[43] Schiller, G., M. Müller and F. Gitzhofer: Preparation of Perovskite Powders and Coatings by RF-Suspension Plasma Spraying, Proceedings of 15 th International Thermal Spray Conference - Thermal Spray: Meeting the Challenges of the 21 st Century 2 (1998), p. 1363-1367.

[44] Bach, F.-W., K. Möhwald, T. Wenz and R. Horstmann: Verarbeiten von kolloidal gelösten Nanopartikeln durch Thermisches Spritzen, Proceedings of Tagungsband zum 7. Werkstofftechnischen Kolloquium (2004), p. 232-237. 
[45] Bonneau, M., F. Gitzhofer and M. Boulos: $\mathrm{SOFC} / \mathrm{CeO}_{2}$ Doped Electrolyte Deposition Using Suspension Plasma Spraying, Proceedings of 1st International Thermal Spray Conference - Thermal Spray: Surface Engineering via Applied Research 1 (2000), p. 929-934.

[46] Bouyer, E., M. I. Boulos and F. Gitzhofer: Suspension Plasma Spraying for Coating and Power Preparation: The Case of Hydroxyapatite, Proceedings of Surface Modification Technologies X Book No 668 (1997), p. 292-305.

[47] Boyer, E., F. Gitzhofer and M. Boulos: Parametric Study of Suspension Plasma Sprayed Hydroxyapatite, Proceedings of 9th National Thermal Spray Conference - Thermal Spray: Practical Solutions for Engineering Problems (1996), p. 683-691.

[48] Delbos, C., J. Fazilleau, V. Rat, J. F. Coudert, P. Fauchais and L. Bianchi: Finely structured ceramic coatings elaborated by liquid suspension injection in a DC plasma jet, Proceedings of ITSC 2004 Thermal Spray Solutions Advances in Technology and Applications (2004), p. 1-6.

[49] Fazilleau, J., C. Delbos, M. Violier, J.-F. Coudert, P. Fauchais, L. Bianchi and K. Wittmann-Ténèze: Influence of Substrate Temperature on Formation of Micrometric Splats Obtained by Plasma Spraying Liquid Suspension, Proceedings of ITSC 2003 International Thermal Spray Conference - Advancing the Science and Applying the Technology 2 (2003), p. 889-893.

[50] Kumar, R., P. Cheang and K. A. Khor: Phase composition and heat of crystallisation of amorphous calcium phosphate in ultra-fine radio frequency suspension plasma sprayed hydroxyapatite powders, Acta materialia 52 (2004), p. 1171-1181

[51] Kuroda, S. and P. Blazdell: Suspension plasma spraying of ceramics by using an ink jet printer - SuspensionsPlasmaspritzen von Keramiken mit einem Tintenstrahldrucker, Proceedings of ITSC 2002 International Thermal Spray Conference 1 (2002), p. 539-543.

[52] Monterrubio-Badillo, C., H. Ageorges, T. Chartier, J.-F. Coudert and P. Fauchais: Plasma Spraying of a Perovskite Suspension for SOFC Cathodes, Proceedings of ITSC 2003 International Thermal Spray Conference - Advancing the Science and Applying the Technology 1 (2003), p. 687-692.

[53] Mueller, M., R. Henne, G. Schiller, M. I. Boulos, F. Gitzhofer and R. B. Heimann: Radio-Frequency Suspension Plasma Spraying of Cobalt Spinel Anodes for Alkaline Water Electrolysis, Proceedings of 15th International Thermal Spray Conference - Thermal Spray: Meeting the Challenges of the 21 st Century 2 (1998), p. 1523-1527.

[54] Rat, V., C. Delbos, J. Fazilleau, J. F. Coudert and P. Fauchais: Dense zirconia electrolyte by suspension D.C. plasma spraying, Proceedings of 12th Workshop Plasma Technology (2004), p. 89-104.

[55] Schiller, G., M. Müller and F. Gitzhofer: Suspension Plasma Spraying for the Preparation of Perovskite Powders and Coatings, Proceedings of Ist United Thermal Spray Conference - Thermal Spray: A United Forum for Scientific and Technological Advances (1997), p. 349-352.

[56] Siegert, R., J.-E. Döring, J.-L. Marqués, R. Vaßen, D. Sebold, D. Stöver and D. Jülich: Denser Ceramic Coatings obtained by the Optimization of the Suspension Plasma Spraying Technique, Proceedings of ITSC 2004 Thermal Spray Solutions - Advances in Technology and Applications (2004), p. 13-18.

[57] Bhatia, T., A. Ozturk, L. Xie, E. H. Jordan, B. M. Cetegen, M. Gell, X. Ma and N. P. Padture: Mechanisms of ceramic coating deposition in solution-precursor plasma spray, Journal of Materials Research 17 (2002), p. 23632372 .

[58] Liu, S. and F.-C. Liao: Precipitate Stability in the Heat Affected Zone of Nitrogen-Enhanced High Strength Low Alloy Steels, Materials Science and Engineering: A 244 (1998), p. 273-283. 


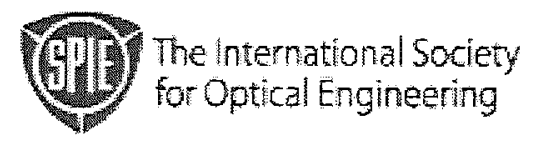

Furthering Innovation in Optics and Photonics

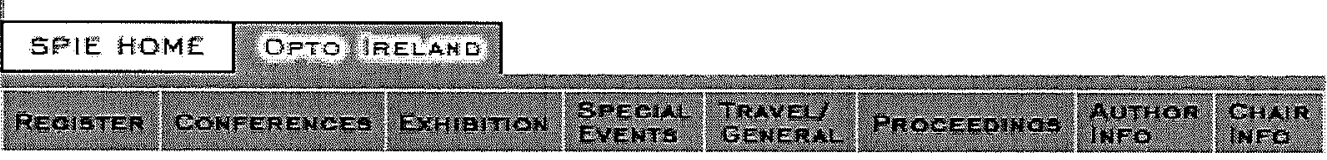

\section{Opto Ireland 2005 \\ MEETING WRAP-UP}

\section{Bennachtaí agus Dea Ghuidhe as Eireann!}

...meaning "Blessings and good thoughts from Ireland" or in short - Greetings from the Emerald Isle! We're in Dublin with our last day at OPTO-Ireland 2005 and things are beginning to wind down.

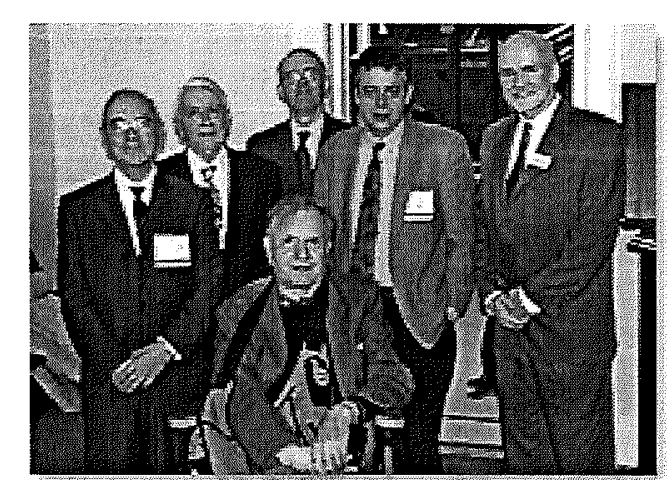

Dan Bradley (front), Frank Imbusch, Kevin Carroll, Thomas Glynn, James Lunney, Eugene Arthurs at the Monday morning Optics Retrospective.

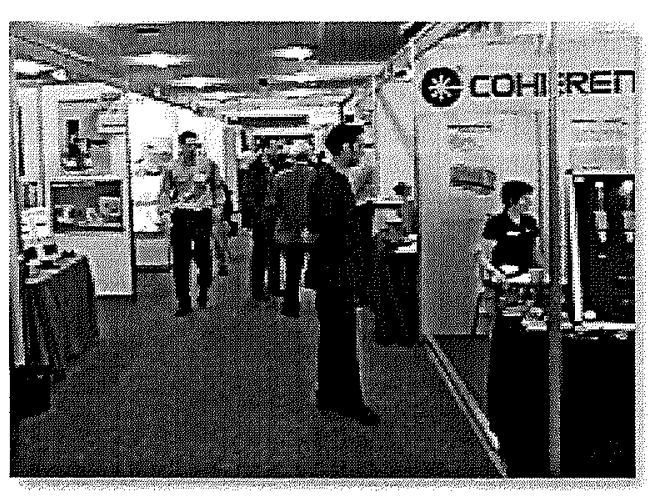

OPTO-Ireland delegates browse the booths at the exhibition.

Media \& Publicity

- Letters of Invitation for Visa Process 